\title{
MEDICINA ALTERNATIVA
}

\section{A experiência da diocese}

\section{de Ji-Paraná}

Mari Solange Cella*

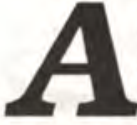

Diocese de Ji-Paraná abrange o centro-leste do Estado de Rondônia e o extremo oeste de Mato Grosso, perfazendo uma área de $250.000 \mathrm{~km}^{2}$.

É uma região de ocupação recente, cuja população é formada, na sua grande maioria, de migrantes vindos das mais diversas regiões do país. Foram atraídos por propagandas dos governos e incentivados por planos econômicos criados para, entre outras razões, desafogar as tensø̃es sociais do sul do Brasil. A década em que mais chegaram migrantes foi a de 80 , cerca de 938 mil, porém as cidades tiveram sua maior taxa de crescimento na década de $70 .{ }^{1}$

Mato Grosso e Rondônia são Estados periféricos num país doente. As cidades se enchem de pessoas expulsas do campo, forçadas pela concentração de terras nas mãos de um pequeno grupo de latifundiários, pela falta de infra-estrutura rural, escolas, postos de saúde, estradas, preços nos produtos. Abandonam os lugares onde moravam ou a posse que mantinham, trabalhando como meeiros, posseiros ou assalariados, quando não em regime de escravidão, em condições de miséria. Vêm para a cidade, em busca de vida melhor. Chegando às cidades, nem sempre encontram lugar e teto, passando a viver em locais subumanos, sofrendo com a falta de saneamento básico, desemprego, alto custo de vida, fornecimento precário de energia, taxas exorbitantes de luz e água, IPTU, transporte coletivo. Ai, não são mais lavradores, tampouco, operários. Muitas familias mantêm seus filhos na

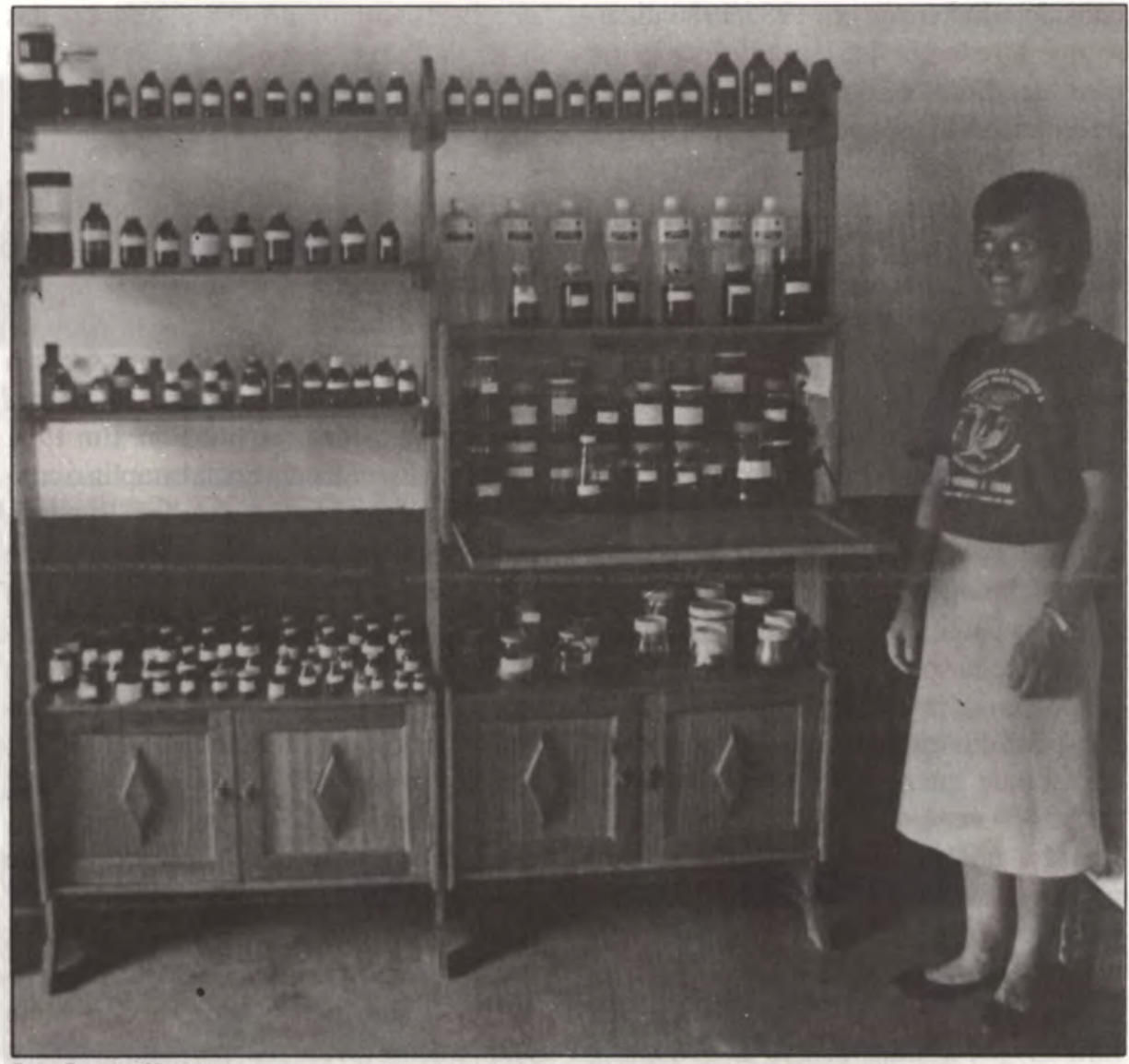

Foto: Douglas Mansur

cidade e os pais vivem num constante vai e vem entre as zonas rural e urbana, à procura de trabalho. Nessas condições de vida, saúde é muito mais que assistência médica, é luta pela conquista de vida digna.

Desta situação vivida pela população originam-se diversas doenças endêmicas e até epidêmicas, como hanseniase, sarampo, meningite, febre amarela, cólera e malária.
Fica evidenciado o sucateamento da Saúde Pública, constatado na ausência demédicos e outros profissionais da saúde, na falta de medicamentos básicos nos postos e centros de saúde, na falta de profissionalismo de médicose outros trabalhadores da saúdee no descaso dos órgãos governamentais para com os profissionais e agentes, provocando paralisações e até fechamento de hospitais, postos e centros de saúde. 


\section{Doenças mais comuns}

Um levantamento feito pela Diocese de Ji-Paraná revelou que a malária $\mathrm{vem} \mathrm{cm}$ primeiro lugar, com $95 \%$ dos casos. Verminose, diarréia, desidratação, pneumonia, leischmaniose, tuberculose, infecções respiratórias e hanseniase também estão presentes em números assustadores de casos.

Falta vontade política para o combate da malária. Não se investe no tratamento. principalmente na região de Mato Grosso. São muitos os casos que levam à morte. As outras doenças são causadas, especialmente, pela falta de saneamento básico e falta de higiene.

O levantamento, que aconteceu em 1992, veio confirmar o que de há muito já se sabia e foi decisivo, em nivel diocesano, para a implementação de um trabalho alternativo na área da saúde.

\section{A denúncia como serviço}

O trabalho feito pela Pastoral da Saúde da Diocese de Ji-Paraná é um sinal muito concreto de que, com boa vontade, é possivel melhorar a saúde do povo. Quando se percebeu que a população estava sendo destratada na saúde, decidiu-se que era o momento de ações concretas para minimizar o problema.

A Pastoral da Saúde, junto com seu trabalho curativo e preventivo, realiza um serviço político de denúncias sobre os sistemas políticos, comercialização da saúde e da doença, a ação das empresas farmacêuticas, os desvios de verbas públicas que deveriam reverter à saúde, o não funcionamento dos Conselhos Municipais de Saúde e a não participação dos grupos organizados nos mesmos, a omissão dos serviços de saúde sobre as doenças endêmicas e epidêmicas e a esterilização em massa de mulheres $\mathrm{em}$ plena idade fértil com fins eleitoreiros.

\section{Ações}

Os agentes de saúde não fazem apenas "consultas". Há uma proposta de ação e reflexão incentivando a apropriação do processo de produção de saúde pelo povo, a organização $\mathrm{cm}$ grupos para a discussão e encaminhamento dos problemas das comunidades e, principalmente, a apropriação dos direitos garantidos pela Constituição, mas que não são cumpridos.

São mais de 1100 agentes de saúde voluntários e quatro agentes de saúde remunerados. $\mathrm{O}$ número de agentes voluntários se multiplica à medida das necessidades de cada comunidade local. De 1988 até 1993 haviam participado de Cursos de Formação oferecidos pelo Projeto Pe. Ezequiel $^{3} 1124$ agentes de saúde comunitários voluntários.

Para ser agente de saúde é necessário ter boa vontade, espírito de solidariedade, bom senso e ser alfabetizado. O último critério nem sempre é levado em conta. As pessoas, primeiro tornam-se agentes de saúde, em seguida vão aos cursos de alfabetização de adultos devido à necessidade que sentem. Mais uma ação concreta da Pastoral da Saúde! Os agentes recebem formação constante em cursos diocesanos ou paroquiais, são treinados e prestam serviços à comunidade voluntariamente. Tanto nos cursos de formação e treinamento como no trabalho diário dos agentes, três preocupações constituem foco permanente de atenção: a orientação geral $\mathrm{em}$ saúde; políticas de saúde e o cuidado com os doentes.

Onze agentes estudaram Homeopatia no IPESP (Instituto Pastoral em Saúde Popular), en Cuiabá/MT. Há Farmacêuticos Homeopáticos responsáveis pela manipulação de medicamentos, atendimento e assessoria aos agentes comunitários.

Na Diocese cxistem cerca de 100 farmácias comunitárias de medicina alternativa e homeopatia. As "farmacinhas" funcionam também como Centros de Treinamento para os agentes de saúde. Ali eles se encontram para estudar, trocar experiências e adquirir matrizes homeopáticas. Em cada local de treinamento há um agente que acompanha e orienta os trabalhos dos demais.

São realizadas diversas manifestações públicas reivindicando a melhoria no atendimento na Saúde Pública onde a palavra é aberta à população e também ao poder público.

Os agentes de saúde, ao realizar seu trabalho, retomam uma prática há muito abandonada pelos profissionais da saúde: a escuta. As pessoas, ao se dirigir às 'farmacinhas', chegam movidas pela necessidade causada pela doença e, precisam, acima de tudo, de serem ouvidas. Ouvidas não apenas pela sua falta de saúde, mas, principalmente, pelas causas que fazem a doença surgir. Aí entra a dimensão politica do serviço: a tomada de consciência dessas causas e da responsabilidade da própria população em reverter a situação através da apropriação do direito à cidadania de cada pessoa.

A pessoa com problemas de saúde, ao ser atendida, é aconselhada em relação à alimentação, com ênfase na utilização da cozinha alternativa e sem agrotóxicos, e incentivada ao cultivo das ervas medicinais. É orientada sobre os cuidados com a horta medicinal, o preparo das ervas e dos chás. A orientação estende-se, ainda, aos cuidados básicos de higiene pessoal, dos alimentos e da casa e ao saneamento básico.

Um número significativo de agentes comunitários da saúde oferece serviços de massagens. Todos os agentes são treinados para o conhecimento do corpo humano e das funções especificas de seus órgãos e aparelhos.

Os agentes realizam, igualmente, diversas atividades envolvendo a população, como gincanas da saúde em escolas, exposição de ervas, troca de experiências e o resgate do saber popular relacionado às plantas medicinais.

Uma grande ação conjunta é a participação ativa nos Conselhos Municipais de Saúde, embora haja grande dificuldade em ser aceitos e ter voz ativa devido às exigências que fazem para a melhoria do atendimento à saúde da população.

$\mathrm{O}$ atendimento à população é gratuito, sendo que os medicamentos manipulados pelos responsáveis legais são cobrados a preços acessíveis para o ressarcimento da vidraria e matrizes utilizadas. Isto, mais a falta de assistência da Saúde Pública e os ótimos resultados curativos e preventivos obtidos, ocasionam grandes filas para o atendimento. Há uma preocupação muito grande para que as "farmacinhas" não se tornem um substituto dos órgãos responsáveis pela Saúde Pública. A Pastoral da 
Saúde faz o trabalho para evitar maiores conseqüências à população. $\mathrm{O}$ seu objetivo maior é o trabalho de devolver ao povo a sua cidadania e incentivá-lo à cobrança de seus direitos.

\section{Repercussão Popular}

O serviço prestado pelos agentes repercute favoravelmente na população, não só naquela mais atingida pela falta de atendimento à saúde, mas por pessoas que têm acesso aos serviços não gratuitos da medicina. $\mathrm{O}$ atendimento é franqueado a todos. as pessoas conseguem adquirir os medicamentos de que necessitam, são atendidas dignamente, adquirem conhecimentos sobre plantas medicinais e os bons efeitos curativos acontecem. Na necessidade, sabem aconselhar a procura da medicina alopática. Os agentes de saúde são enfáticos nesse ponto: a medicina alopática, $\mathrm{em}$ certos casos, é necessária, não podendo ser substituida; falta-lhe, entretanto, a revisão de certos conceitos e a valorização da pessoa humana. A população deixa de ser explorada pelos farmacêuticos e hospitais privados. O envolvimento das comunidades e das escolas está se tornando cada vez maior. principalmentecom relaçãoao plan- tio das ervas medicinais, o reconhecimento das mesmas e o estudo sobre elas. A eficácia do tratamento nas doenças mentais, nervosas e psíquicas também se faz notar. Após otratamento a pessoa sente-se integralmente recuperada.

\section{Dificuldades}

Apesar de tudo, as dificuldades se fazem presente. Como são voluntários, os agentes dispõem de pouco tempo para o atendimento. Precisam, também, exercer serviços que thes garantam a sobrevivência. A dificuldade em conciliar o trabalho particular ou o doméstico com o de agente de saúde é grande. Nem sempre é possivel escolher a hora de ser atendido pelo agente. Algumas comunidades estão reivindicando junto às autoridades competentes, a contratação legal dos agentes para prestarem serviços juntos aos Postos de Saúde na zona rural. É um longo e burocrático caminho, mesmo porque há o impedimento do exercício da medicina por leigos, embora possuam formação técnica e não manipulem medicamentos. As autoridades criticam ferozmente a prática da medicina alternativa, chegando, em alguns casos. às ameaças de represálias. O material tem custo elevado e é de difícil aquisição. $\mathrm{O}$ número de agentes é muito pequeno, comparado com a necessidade. Deseja-se evitar, a todo custo, as filas, o chegar de madrugada para ser atendido, o acúmulo de pessoas doentes para um só agente, o que se tornaria uma cópia dos problemas verificados nos postos e hospitais públicos.

Ao se prestar o atendimento, percebese que, na maioria das vezes, não é suficiente o chá, o medicamento homeopático, as orientações básicas para higiene e alimentação. Precisa-se, com urgência, de meios para a aquisição do alimento, de meios para o saneamento básico nas residências. Urge o saneamento básico nas cidades. É imprescindivel que haja empregos com remuneraçâo digna, que haja terra para os agricultores e uma politica agricola justa, estradas e condições de transporte.

As dificuldades são muitas, mas os resultados são altamente satisfatórios e animadores, principalmente pela retomada de consciência da população de seus direitos como cidadãos. Os agentes sabem que, no momento, este trabalho representa a saída possivel na questão da saúde, para o povo.

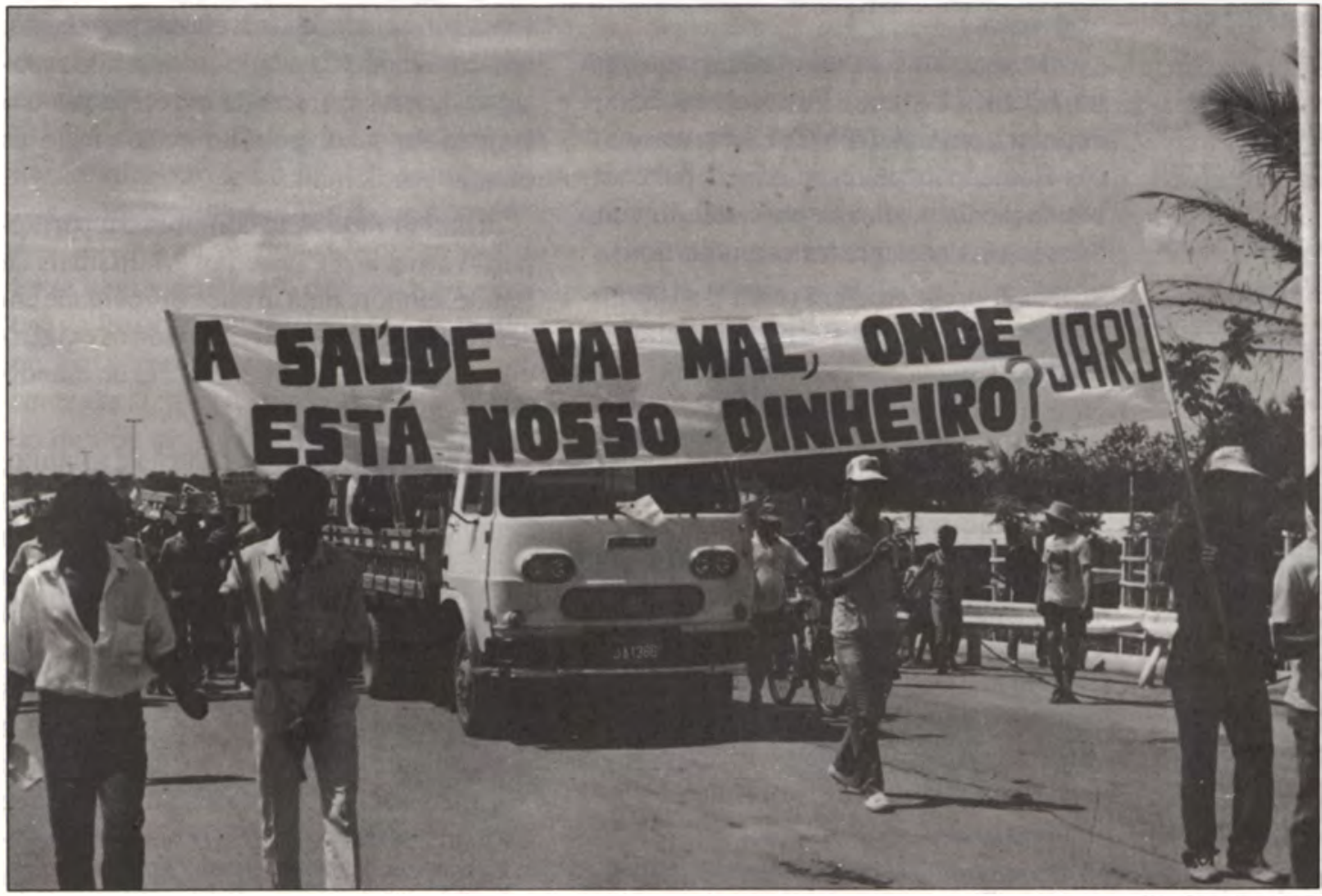

Foto: Luiz Bassegio
*MariSolange Cellaécourdenadora das Pastorais Sociais na Diocese de Ji-Paraná, integrante do CEPAMI (Centro de Estudos e de Pastoral dos Migrantes) e Profe licenciada em Quimica e Matemática.

\section{NOTAS}

1. O Migrante - Ano VI, n 24. fevi92.

2- Diocese de Ji-Paraná - Levantamento de dados da realidade da saúde pública nos municipios da regiâo da Diocese de JiParana - RO/MT - 1992, mimeo 3. O Projelo Pe.Ezequiel da Diocese de Ji-Paraná coordena atividades que abrangem qualro setores de trabalho: Saúde, Menor. Allabetização e Agricultura. tentando uma resposta aos problemas sociais que afligem a população 